\title{
Assessing Contribution Collection: A Case of SOCSO's IPS
}

\author{
Mohd Zaki Awang Chek, Isma Liana Ismail, Nur Faezah Jamal
}

\begin{abstract}
Currently, Social Security Organization (SOCSO) administers two types of protection schemes namely the Employment Injury Scheme (EIS) and the Invalidity Pension Scheme (IPS). Both schemes are effective once employers make contributions to SOCSO. These contributions are taken $2.25 \%$ of an employee's monthly gross income. Recent statistics show that, the excess of SOCSO's IPS claims amounted to RM4.5 billion, which was an increase of $19.7 \%$ from the previous year. Yet, the contributions only amounted to RM4.3 billion. This critical situation assessed using single linear regression modelling and it can be solved by improving the current SOCSO's IPS funding system. As suggested in this study, the funding system could be made more effective through an increase of the fund collection by raising the current contribution rate. The contribution rate is determined through recent social and economic data, such as current mortality rate and interest rate.
\end{abstract}

Keywords: Contribution rate, invalidity pension scheme, regression analysis, SOCSO.

\section{INTRODUCTION}

In Malaysia, the SOCSO's contribution rates are distributed into two schemes, namely the EIS and the IPS at $1.25 \%$ and $1.0 \%$ respectively. Based on the contribution rate, payment of contribution is shared between the employer and the employee. Contributions to SOCSO are made by employees having a gross monthly income of less than RM3,000.00 per month. However, it is relevant to consider the contribution rate would have to be adjusted upwards by SOCSO in the near future to ensure that all claims can be sufficiently met [1]. Recently, the excess of SOCSO's IPS claims amounted to RM4.5 billion, which was an increase of $19.7 \%$ from the previous year. Yet, the contributions only amounted to RM4.3 billion. The yearly pattern of claims has been trending upwards for the last five years. It is because since 1969, many significant changes have occurred in the workplace. Working conditions have changed significantly and new jobs have been created due to advancements in technology [2]. That study seeks to fill the gap inherent in socio-economic environment for SOCSO's financial protection system within the context of the country's broader social security framework. As a single fund manager of social insurance created for the lower- and middle-income group in

Revised Version Manuscript Received on September 16, 2019.

Mohd Zaki Awang Chek, Faculty of Computer and Mathematical Sciences, Center for Actuarial Studies, Universiti Teknologi MARA, Tapah, Perak, Malaysia.

Isma Liana Ismail, Faculty of Computer and Mathematical Sciences, Center for Statistics and Decision Science, Universiti Teknologi MARA, Tapah, Perak, Malaysia.

Nur Faezah Jamal, Faculty of Computer and Mathematical Sciences, Center for Statistics and Decision Science, Universiti Teknologi MARA, Tapah, Perak, Malaysia.
Malaysia, SOCSO is obligated to make sure that all future payments towards employees' claims be made regardless of any current and economic situation, as spelled out in the Employee Social Security Act 1969. In order to fulfil its obligations on all future claims of employees, SOCSO should have a dynamic and strong financial system. Despite this, the IPS's fund collection is in deficit as compared to the amount it has paid out for claims.

Therefore, this critical situation can be solved by improving the current SOCSO's IPS funding system. As suggested in this study, the funding system could be made more effective through an increase of the fund collection by raising the current contribution rate. The contribution rate is determined through recent social and economic data, such as current mortality rate and interest rate. The empirical findings would be useful for SOCSO since SOCSO's IPS used toward comprehensive contribution rate would serve as a reference or guideline for SOCSO in making future decisions. Based on the above scenarios, this study is conducted to predict SOCSO's IPS using simple linear regression modelling.

\section{LITERATURE REVIEW}

The regression analyses have been employed in numerous researches since these few years because such methods offer useful information for data analyses [3]. As such this section unfolds the discussion of several researches pertaining to collection of funds and payments of claims practiced by both the governmental and non-government insurance industry. Furthermore, the approaches of regression have been employed by these studies in examining data, besides estimating the results of fund collection, as well as expenses [4]. On the other hand, in [5] investigated the use and the expenses of healthcare among Brazilians who received coverage from private healthcare schemes four years prior to death. For that purpose, data were retrieved from death certificates and files obtained from medical scheme agent, hence the subjects were comprised of 274 health scheme recipients deceased in years 1998, 1999, and 2000. The literature depicts some essential aspects of the study from the stance of inferential. Besides, crucial approaches taken to overcome some issues in present organizations are elaborated as well. Thus, this particular study adopts inferential analysis to forecast the SOCSO's IPS contribution collection. 


\section{METHODOLOGY}

\section{A. Research design}

Trend analysis of SOCSO's IPS funding contributions collected made was analysed. Research design was adopted for this particular study which time series data (1985-2018) study using simple linear regression was employed for the study on predicted future contribution collection within a span of five years, from 2019-2023. This study falls under the exploratory study category, a design that is applicable when not much is known about the situation at hand, or no information is available on how similar problems or research issues have been resolved in the past. The type of investigation selected for this research was causal research to identify cause-and-effect relationship. All factors such as mortality rate, entry age, retirement age, entry salary, salary increment, and interest rate modify an outcome, would also be affected and influence SOCSO's IPS contribution rate. In other words, this type of investigation on claims payments' influence on contribution rate is most suitable when a study seeks to define the cause of insufficient claims payment [6]. This study was conducted on longitudinal (also known as time series) time horizon since the data were gathered from 1985 to 2018 from SOCSO's archive. Longitudinal study involves the collection of data across more than one point of time in order to answer the research questions [7].

\section{B. Sampling design} elements of population, sampling frame, sampling technique, and sample size used is justified below. All Malaysian active employees were included. Therefore, a census was carried out in this study whereby every active registered employee in Malaysia was evaluated. This is known as a complete enumeration, referring to the complete count for this study. As stated in the time horizon section, this study was conducted on a time series basis since the data were gathered from 1985 to 2018 from SOCSO's archive. This is subject to availability and confidentiality of the required data from the relevant SOCSO Department.

\section{Data analysis}

In data analysis, linear regression is an approach for modelling the relationship between a scalar dependent variable, $y$, and one or more explanatory variables (or independent variables) denoted as $x$. The case of one explanatory variable is called a simple linear regression. The data gathered comprised 33 observations from 1985 to 2018 . When a line was fitted through the scatter plot, the regression line revealed the estimated contribution collection and claim payments for a given year [8]. As mentioned, the key measure to the validity of the estimated linear line is $r^{2}$. The last step for the linear regression analysis is the test of significance. Linear regression uses the significance of each coefficient and the intercept. In [9] that the following seven assumptions are made by simple linear regression models with standard estimation techniques, namely as sample size, linear relationship, multivariate normality, homoscedasticity, little multicollinearity, outliers and no auto- correlation.
In this study, the sampling design which includes the

\section{RESULTS AND DISCUSSION}

For a regression model to generalize a study, it should be ascertained that the underlying assumptions have been met. A test should also be performed to determine whether the model does generalize the study, and to cross-validate it. Simple Linear Regression (SLR) is only appropriate when the following conditions are satisfied sample size; linear relationship; multivariate normality; homoscedascity; little multicollinearity; outliers; and no auto- correlation. The results of the simple linear regression for the predicted SOCSO's IPS contribution collection are presented for the period between 2019 and 2023; after all of the seven assumptions have been checked and validated.

Since the contribution collection data met all 7 assumptions for the simple linear regression, this section will discuss the simple linear regression of the forecasted contribution collection from 2019 to 2023. The dependent variable is the contribution collection, and the independent variable is duration of the data (33 years, from 1985 to 2018). Table 1 and Fig. 1 show the forecasted contribution collection from 2019 to 2023 based on historical data.

Table 1: Forecasted contribution collection from 2019

to 2023

\begin{tabular}{|l|l|}
\hline \multirow{2}{*}{ Year } & Forecasted Amount $(\mathbf{R M})$ \\
\cline { 2 - 2 } & $\mathbf{y}=\mathbf{3 8 , 2 4 4 , 3 1 0 . 8 2}$ (Year) $\mathbf{~ 1 1 3 , 1 5 4 , 8 3 8 . 7 2}$ \\
\hline 2019 & $1,225,396,039.98$ \\
\hline 2020 & $1,263,640,350.80$ \\
\hline 2021 & $1,301,884,661.62$ \\
\hline 2022 & $1,340,128,972.44$ \\
\hline 2023 & $1,378,373,283.26$ \\
\hline
\end{tabular}

Forecasted Contribution Collection Till 2023

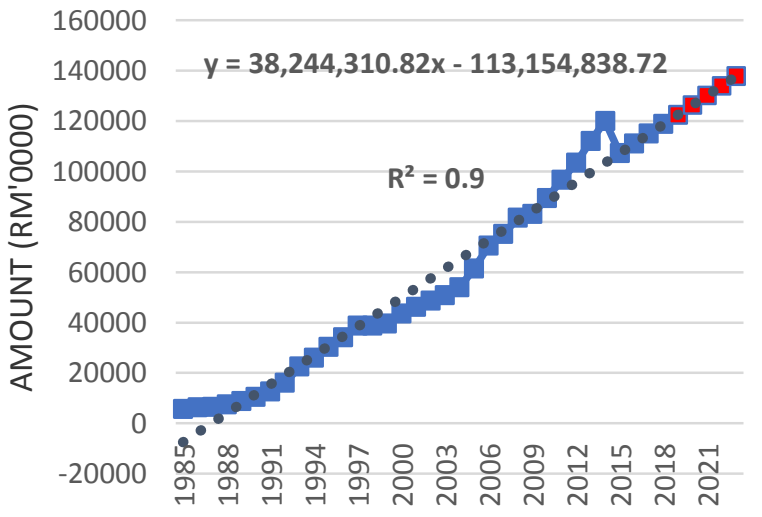

Fig. 1: Forecasted contribution collection from 2019 to 2023

Fig. 1 shows the scatter diagram for SOCSO's IPS according to the data given in Table 1. The trend showed a nearly perfect relationship between the contribution collection and the year. The prediction equation for the contribution collection as shown by (1),

Contribution Collection, $\mathrm{y}=38,244,310.82$ (Year) $113,154,838.72$

(1) 
This linear equation shows that the contribution collection is predicted to increase by $38,244,310.82$ when the independent variable (year) increases by one unit. This model is significantly better at predicting SOCSO's IPS contribution collection in the future. This is because the F-ratio is 664.807, which is highly significant $(p<0.001)$. Thus, these results prove that the model has significantly improved the ability to predict SOCSO's IPS contribution collection from 2019 to 2023 . The R-squared $\left(r^{2}\right)$ of the regression is the fraction of the variation in the contribution collection that accounted for by the independent variable (year). The R-squared for (1) is $98 \%$. Evidently, $2 \%$ of the variations cannot be explained by year. This may be due to other factors that have not been included in the equation [10]. This study seeks to analyze the trend of the contribution collection as against the independent variable (year). In (1) indicates that the predicted contribution collection will gradually increase from 2019 to 2023. In this study, the regression of year as the independent variable and its coefficient indicate that the dependent variable for SOCSO's IPS contribution collection can be expected to increase significantly with the passing of each year. The contribution fund collection is predicted based on available past information. It concerns the amount of losses, and the frequency exposure to risk [11].

\section{CONCLUSION}

According to the annual report issued by SOCSO, it appears that there is a deficit of the IPS fund distributed. In 2002, the total distribution was recorded at RM369.8 million. The increase in the next five years brings the total allocation to RM633.24 million. In 2014, a total of RM1.5 billion in IPS funding was successfully distributed accordingly to eligible claimants in Malaysia via the seven types of benefits [12]. The insufficiency of contribution collected can be seen since 2010, where the trend shows an increasing number of claim payments over the years. This shows that the current contribution rate applied by SOCSO is deficient. Findings based on analyses of frequency show that the number of recipients under the IPS distributed according to the 7 types of benefits from 2002 to 2014 form the largest share and given to the Invalidity Pension and Grant, totaling $40 \%$ of the total fund collected [13]. The above findings indicate that the current contribution rate should correspondingly increase, especially in regard to the long-term IPS benefits. Between 2013 to 2014, the number of IPS's recipients (claimants and dependents) increased drastically by $72.19 \%$. Thus, SOCSO needs to seriously look into this matter by creating effective prevention programs to curb this phenomenon. Apart from that, a majority of cases involved fatal accidents while travelling from or to the workplace. Nevertheless, in the recent years, there is sign of rapid increase in the number of fatal accidents occurring in the workplace.

\section{ACKNOWLEDGMENT}

This study was partially supported by UiTM Perak Branch. We thank our colleagues from Universiti Kebangsaan Malaysia (UKM) and Social Security Organisation (SOCSO) who provided insight and expertise that greatly assisted the study. We thank Prof. Dr. Zuriah Ab. Rahman for assistance, and Prof. Dr. Nuriszura Ismail for comments that greatly improved the manuscript.

\section{REFERENCES}

1. W. Lean, SOCSO contribution may be raised. Selangor: The Star, 2010.

2. Population Reference Bureau, Social security systems around the world. Available: https://www.prb.org/socialsecurity/.

3. N. G. Levinsky, W. Yu, A. Ash, M. Moskowitz, G. Gazelle, O. Saynina, and E. J. Emanuel, "Influence of age on Medicare expenditures and medical care in the last year of life," J. Am. Med. Assoc., 286 (11) , 2001, pp. 1349-1355.

4. A. Venema, A. Bloemhoff, J. F. Ybema, and C. A. Stam, "Monitoring occupational accidents in the Netherlands: Does it work for prevention?," Saf. Sci. Monit., 11(2), 2007, pp. 1-8.

5. M. B. Ferraz, I. C. Miranda, J. Padovan, P. C. De Soárez, and R. Ciconelli, "Health care costs in the last four years of life for private health plan beneficiaries in Brazil," Pan Am. J. Public Heal, 24(2), 2008, pp. 120-126.

6. W. G. Zikmund, B. J. Babin, J. C. Carr, and M. Griffin, Business Research Methods. Canada: South-Western Cengage Learning, 2013.

7. U. Sekaran and R. Bougie, Research Methods for Business. Italy: Wiley, 2013.

8. P. C. Verhoef and B. Donkers, "Predicting customer potential value an application in the insurance industry," Decis. Support Syst., 32(2), 2001, pp. 189-199.

9. Field, Factor analysis using SPSS. Available: http://www.users.sussex.ac.uk/ andyf/factor.pdf.

10. W. Greene, The linear regression model. Available: http://people.stern.nyu.edu/wgreene/MathStat/GreeneCha pter2.pdf.

11. R. Kaas and M. Goovaerts, Modern actuarial risk theory Using R. Berlin: Springer Science and Business Media, 2008.

12. S. C. Seng, Social security: Challenges and issues Available:

http://swrc.um.edu.my/social-security-challenges-and-iss ues/.

13. International Labour Office, "The 9th actuarial valuation report. Available: https://www.ilo.org/wcmsp5/groups/public/---ed_protect/ ---soc_sec/documents/publication/wcms_secsoc_24126.p df. 